\title{
Erratum to: Endomorphisms of the lattice of epigroup varieties
}

\author{
S. V. Gusev ${ }^{1}$ • B. M. Vernikov ${ }^{1}$
}

Published online: 5 October 2016

(C) Springer Science+Business Media New York 2016

\section{Erratum to: Semigroup Forum DOI 10.1007/s00233-016-9825-6}

The correct authors' names for this article are S. V. Gusev and B. M. Vernikov.

The online version of the original article can be found under doi:10.1007/s00233-016-9825-6.

$\triangle \quad$ B. M. Vernikov

bvernikov@gmail.com

S. V. Gusev

sergey.gusb@gmail.com

1 Institute of Mathematics and Computer Science, Ural Federal University, Lenina 51, Ekaterinburg, Russia 620000 